\title{
KEY PERFORMANCE INDICATOR DISCLOSURES THROUGH THE INTERNET: TOWARDS AN INTEGRATED SCOREBOARD
}

\author{
Ilídio Tomás Lopes \\ Iscte Business School - Lisbon University Institute \\ Av. Das Forças Armadas, 1649-026 Lisbon, Portugal \\ ilidio.tomas.lopes@iscte.pt \\ doi:10.13165/ST-14-4-1-03
}

\section{Abstract}

Purpose. Information disclosure is driven by multiple determinants, most of them supported by traditional theories, such as agency theory, contingency theory, and legitimacy theory. This research aims to identify a set of Key Performance Indicators (KPI), disclosed to stakeholders through Internet. It also aims to apply for an integrated performance scoreboard, acting as a dynamic comparative tool, in particular for listed companies whose market value is driven by investor expectations and needs.

Design/methodology/approach. Based on 47 listed companies from the Portuguese Stock Index regulated market, and through an interpretive content analysis, research was driven towards the identification of KPI that were explicitly reported to stakeholders through structured or unstructured frameworks. This qualitative approach supports the evidence on performance indicators reported by listed companies to stakeholders, in particular to potential stockholders.

Findings. Companies disclose a wide variety of key performance indicators, however in most cases included in their periodical management reports. Only some companies disclose those indicators through a visible form in their websites. Furthermore, the disclosed KPI have a generic nature and are usually complemented by theoretical explanations about their evolution and trends. The diversity of indicators disclosed does 
not permit a comparison between companies and activity sectors. Key performance indicators are still disclosed on a voluntarily basis, remaining, within this scope, multiple agency conflicts and other issues around agency costs. Considering the intensity and categorisation of in information disclosure, a standard framework is required in order to ensure a dynamic comparison between companies or sectors.

Research limitations. The scope of this research is the regulated market of Portugal. Further research can include sample companies listed in other European regulated markets or even non-listed companies. The selection of indicators for the proposed framework was based exclusively on frequencies and not on the value and importance attributed to them by stakeholders. Thus, a survey is required in order to certify that the selected indicators are the ones that best fit stakeholder expectations and needs. Furthermore, the research was based on website content and management report analysis that determines a certain level of subjectivity, natural source of interpretation biases.

Practical implications. Empirical evidence is the basis for a structured KPI scoreboard proposal in order to ensure a periodical comparison between companies, from the perspective of external stakeholders.

Originality/value. This paper grants and promotes an integrated overview about the key performance indicators expressly disclosed to stakeholders through Internet by Portuguese listed companies. This evidence has used scoreboard proposal as a basis for towards a comparative analysis in the traditional balanced scorecard perspectives. This scoreboard can be disclosed to the market by companies as a basis for an overall performance evaluation and business comprehensiveness. However, further developments are required, in particular in the domain of policy making. Information disclosed to the market is not regulated enough in order to minimise the performance analysis discretion and overall transparency.

Keywords: corporate reporting, information disclosure, internet, performance, scoreboard.

Paper type: Research paper

\section{Introduction}

Electronic platforms, in particular the Internet, have emerged as a more direct and faster way to reach stakeholders. The range of information disclosed through Internet has been gradually enlarged, in particular electronic financial reporting for companies integrated in stock exchange regulated markets. Business developments and stakeholder expectations and needs have demanded that companies reduce their agency costs and, therefore, intensify their information disclosure. Those information flows are sometimes supported by legal standards and statements, in particular accounting standards, requiring the introduction of some filters and control agents in the systems that ensure accuracy and reliability of the information effectively disseminated. 
Considering that the Internet has become a favoured medium, technological advances have led the new era changes in the means available to corporations, government agencies, and the potential investors to obtain and disseminate information.

Notwithstanding various benefits associated with information disclosure through corporate websites, multiple determinants exist that affect the dissemination intensity flow. Information asymmetry remains one of the main topics, requiring the set of rules and procedures to ensure the quality of information to be disclosed. Furthermore, some costs are associated with collection, presentation and dissemination of information which induces companies to involve in an ongoing management process of information disclosure. The Internet has revolutionised several traditional approaches towards the way that companies do their businesses and manage their information flows (Tapscott et al., 2000). Thus, as business reporting on the Internet becomes more widespread, most market agents and regulators tend to question the acceptability and quality of internet-based business reporting (Khadaroo, 2005). In fact, there are no rules or standards in the scope of performance indicators to be disclosed to the market in a structured framework. Thus, discretionary analysis can be made or perceived by different groups of stakeholders, depending on their knowledge, expectations and beliefs.

This paper intends to identify the main key performance indicators (KPI) disclosed, in an explicit form, by Portuguese listed companies through internet or even other electronic platforms and devices. After being categorised according to the balanced scorecard approach (Kaplan and Norton, 1996), this research also aims to propose a KPI scoreboard, applicable to listed companies. This study also considers the implications of that scoreboard in the future stakeholder perceptiveness. Thus, the paper is structured as follows. A review of relevant literature is provided, by exploring the topic around information disclosure, including its drivers and determinants. The proposed methodology is discussed in Section 3. Empirical evidence is presented and commented in Section 4, followed by a section on lessons learned and directions.

\section{Information Disclosure}

\subsection{Drivers and detractors}

Companies, in particular listed companies, are requested to disseminate information to stakeholders towards integrated business performance overview and activity comprehensiveness. The Internet has emerged as key electronic performance in the information disclosure process (Asbaugh et al., 1999; Gowthorpe, 2004; Khadaroo, 2005; Hunter and Smith, 2009; Aly et al., 2010; Oyelere and Karuppu, 2012; Uyar, 2012; Basuony and Mohamed, 2014), putting organisations and stakeholders in an immediate networked environment. Electronic businesses models (Tapscott et al., 2000), and information and communication technologies have introduced several changes in the society in individuals' behaviour and in organisational rules and procedures (Khadaroo, 2005). Furthermore, stakeholders also expect for 
organisational key performance indicators that enable them to support individual and collective decisions and actions.

In general terms, information disclosure to stakeholders is strongly influenced by several theories, including agency theory principles. Broadly speaking, this theory has been incorporated in multiple scientific fields, particularly in accounting (Demski, 1980), economics (Spence and Zeckhouser, 1971), marketing (Basu et al., 1985), political science (Mitnick, 1986), finance (Fama, 1980; Fontrodona and Sison, 2006), behaviour and organisational culture (Eisenhardt, 1985; Kosnik, 1987; Kulik, 2005) and sociology (White, 1985; Shapiro, 2005). However, the controversy over its usefulness, applicability and validity remains relevant even today. It was developed during 1960s and the early 1970s by several economists, including Arrow (1971) and Wilson (1968). It translates the problem of attitude to risk either by individuals and/ or groups (Ross, 1973). The differentiation of objectives inherent to those parties that leads their attitude is also different. Those are relations between the principal and the agent, metaphorically supported by a contract-oriented behaviour of parties who take different attitudes towards risk (Jensen and Meckling, 1976).

According to Eisenhardt (1989), an agency relationship arises between two or more parties in a designated agent, acting for the other, called the main field in a particular decision. Both parties acting in favour of their own interest, the principal conducts its action to minimise the costs and the agent acts in order to minimise their action. According to Jensen and Meckling (1976), agency costs correspond to the sum of the monitoring costs by the principal (associated with the incentives of the agent and the monitoring process of their activity), expenses of the undertaking by the agent (associated with the resources spent by the agent to compensate the principal for inappropriate actions) and residual losses (associated with the degree of divergence between the agent's decisions and the decisions that potentially maximise the wellbeing of the principal).

The paradigm of the usefulness of information for decision-making is now one of the key issues in the designing process towards information dissemination to their stakeholders. The profound changes that have occurred in the economies in general and in business models in particular, require information to be disclosed in a timely manner and meeting the expectations of its users. In this asymmetrical dialogue (Gowthorpe, 2004), many factors determine the type, timing and intensity with which that information is disseminated. Electronic platforms have assumed critical importance in this dissemination process and have changed the boundaries of businesses (Tapscott et al., 2000), including legal requirements and standards (Asbaugh et al., 1999; Hunter and Smith, 2009; Aly et al., 2010; Uyar, 2012; Basuony and Mohamed, 2014).

Several theories have explained various factors that influence information disclosure drivers. However, it is our understanding that the factors determining the dissemination of information result from a symbiosis between the business complexity and stakeholder needs. Thus, each of those theories find their basis in the social contract established between the company and its stakeholders, creating internal mechanisms to respond to changes occurring in the environment. Listed companies influenced 
by participants in the market tend to reduce agency costs by disclosing large flow of corporate information (Jensen and Meckling, 1976; Basuony and Mohamed, 2014).

The contingency theory assumes a theoretical perspective that contingencies such as size, uncertainty and risk, technology and environmental pressures affect an organisation's development and operating processes. Thus, organisations cannot develop a standard framework to plan, organise and control their own activities. At the same time, institutional theory considers that organisations should adapt to external expectations, so there are external pressures to implement appropriate practices to disseminate information. The fact that organisations tend to implement the same structures and practices over time in response to social requirements is designated in the literature as institutional isomorphism (DiMaggio and Powell, 1991). The theory of legitimacy is based on the notion of the social contract between the reporting entity and the society in which it operates (Guthrie et al., 2004). The dissemination of information is one way to relieve social pressure and legitimate their organisational activities.

The usefulness issue of information management has a diffuse scope based on multiple drivers: the type of information user, their information needs, the emerging pressure from capital markets, the changes occurred in the environment in which organisations develop their activities and even regulatory requirements often resulting from political decisions. Indeed, we cannot link a particular theory to the behaviours of entities and stakeholders regarding the dissemination of information. Those theories have specific determinants that embody individual and collective behaviours. These behaviours derive from the symbiosis assumptions inherent in each particular theory.

Several factors exist that explain the intensity in the information process, in particular through electronic platforms (Asbaugh et al., 1999; Gowthorpe, 2004; Aly et al., 2010; Uyar, 2012; Oyelere and Karuppu, 2012; Basuony and Mohamed, 2014). Thus, evidence shows that information disclosures are significantly associated with company size, which means that large companies provide more mandatory and even voluntary disclosures than SMEs (Wallace and Naser, 1995; Al-Shammari et al., 2008; Mutawaa and Hewaidi, 2010; Dragu and Tudor, 2011; Arvidsson, 2011). Related key profitability indicators, such as ROE or ROA, are not convergent evidence (Wallace et al., 1994; Street and Gray, 2002; Al-Shammari et al., 2008; Broberg et al., 2010; Dragu and Tudor, 2011), which means that other variables exist that drive effective information compliance and disclosure. Despite such evidence, the use of internet in corporate reporting is still driven by multiple determinants that are explored in the next section.

\subsection{Determinants of corporate reporting on the internet}

In the last decades, computer technology has drastically changed the flow of information between organisations that provide and consumers who demand financial data. This platform has created a new mechanism by which individuals and groups can provide a wide range of heterogeneous information to decision makers (Ashbaugh et al., 1999). Indeed, the possibilities offered by the internet for more genuine, timely 
and symmetrical dialogue between organisations and stakeholders have been flagged many times, even today, when dialogue remains limited and asymmetrical and the disseminators of information manage the flow of information (Gowthorpe, 2004), in particular voluntary internet financial reporting practices (Oyelere and Kuruppu, 2012). According to agency theory, principal leads the flow of information disclosed through internet, selecting and manipulating access, in particular to mandatory information. Thus, website efficiency also depends on the facilities available to access and download useful information for each stakeholder's category. As evidenced by Oyelere and Kuruppu (2012), the majority of companies maintain corporate websites to disseminate diversified information, primarily information about the company, and the products and services they offer. Thus, internet is seen as the opportunity to promote themselves and their products and services, with disclosure of financial information being secondary. In fact, fewer companies with active websites use them as a medium for communicating financial information.

The disclosure of information flow through electronic platforms can be influenced by several determinants, such as size, activity sector, profitability indicators, and leverage ratios, among others. The Steering Committee of the Business Reporting Research Project has enumerated a set of potential determinants, acting as enablers or detractors in the process of disclosing financial information through the internet. According to FASB (2000), six key motives can drive the level of financial information disclosure: (1) reducing the cost and time to distribute information; (2) communicating with previously unidentified consumers of information; (3) supplementing traditional disclosure practices; (4) increasing the amount and type of data disclosed; (5) improving access to potential investors form small companies; and (6) up-to-date information through regular maintenance of websites. However, other practical issues should be considered, such as reliability and selective reporting (Uyar, 2012).

Basuony and Mohamed (2014) and Aly et al. (2010) have found that large companies tend to disclose more financial information in order to reduce information asymmetry and also reduce agent costs. Being subjected to more exposure, the firms come under higher pressure, such as listed companies. This evidence is consistent with agency theory stating that large firms attempt to reduce high agency costs associated with information asymmetry between market participants, by disclosing a large flow of corporate information. Furthermore, companies tend to disclose more information as an attractiveness mechanism by reducing the expected cost of capital (Aly et al.,2010). However, there is no linkage between this type of information and key performance indicators explicitly disclosed.

Broadly speaking, listed companies are required to disclose financial information as stated in regulated stock market regulations. Those companies are obliged to publicly communicate financial information and produce quarterly management reports, make announcements to investors, disclose important events by press releases, and inform stakeholders about social and environmental responsibility activities through their corporate websites. As evidenced by Uyar (2012), companies utilise the internet actively as a communication tool for investor relations by disclosing financial and non-financial information. However, some items are not disclosed as much as others 
that require additional developments to increase the transparency of the companies. Key performance indicators are included in the management reports through nonstructured frameworks, inducing stakeholders to undertake a dynamic discretionary analysis on company integrated performance.

The use of internet has effectively changed the way and the timeliness to reach stakeholders (information on topics, such as corporate overview; stockholder information; and financial information). Markets that suffer from low liquidity, firms that invest in internet technology are able to use the electronic medium to attract investors from abroad, analysts, and creditors who might have otherwise consider the emerging market securities within their portfolios (Hunter and Smith, 2009). As mentioned by Tapscott et al. (2000), network economics drive the interlinked phenomena of increasing returns and network effects. Information as the raw material in the decision-making process experiences a new intensity flow and rules, in many cases reaching stakeholders even in an unstructured way and without being subjected to any filter for accuracy and reliability.

\section{Methodology}

This research analyses the extent to which and whether information on performance indicators is disclosed to stakeholders through the internet. It is based on 47 non-finance companies, all of them listed in the Euronext Lisbon regulated market, with reference to 31 December 2013. Companies were aggregated according to seven activity sectors: media and advertising (6.4\%); petrol and energy (12.8\%); consumer materials (6.4\%); technologies and communications (14.9\%); construction and infrastructures (14.9\%); equipment and industry (21.3\%); consumer services and transportation $(23.4 \%)$, as illustrated in the graph below.

Through content analysis (Abraham and Cox, 2007), company websites were explored in the first step in order to find explicit management control indicators (visible data) disclosed to stakeholders. In the second step, the content of annual management reports (invisible data) was explored to identify KPI that were effectively disseminated in a specific performance section analysis, independently of their structured or unstructured framework. Social and environment reports were excluded from this analysis. The data collected was based on visible and invisible data by using the most common web browsers, such as the Internet Explorer or Google Chrome. For invisible data, we have analysed the annual reports (performance analysis section) for the economic year of 2013. However, in 17 cases (27.7\%), the annual reports of this year have not been disclosed yet. Thus, in this case the last annual report available was used (2012). Explicit performance indicators were registered and counted for frequency purposes. The content analysis was carried out during May 2014.

In the third step, KPI were associated with the Balanced Scorecard (BSC) perspective (Kaplan and Norton, 1996), namely financial perspective, market perspective, internal processes perspective, and learning and growth perspective. This stage was based on an interpretive approach (Ryan et al., 2002; Sekaran and Bougie, 2013), by linking 
the theoretical framework of BSC with performance indicators disseminated by companies. Thus, a theory is used to provide insights in organisational actions, despite the intrinsic subjective interpretation and agreement in the categorisation linkage.

\section{Evidences and Discussion}

Performance analysis is traditionally based on a set of key performance indicators disseminated to stakeholders in a direct/indirect way by using several structured/ unstructured frameworks. In this research we have found that only 7 companies (14.9\%) directly disclose a set of KPI in their websites. Other companies include those indicators in a dispersed way and in their periodical management reports, but in an identified section for the purposes of performance analysis. As required by regulated market rules, information for investors should be disseminated through identified links, in compliance with the regulatory requirements. All websites were updated, namely the announcements made to regulated market as required by regulatory guidelines.

Table 1. Main Financial KPI indicators

\begin{tabular}{|c|l|l|c|c|}
\hline KPI & \multicolumn{1}{|c|}{ Description } & Measure & $\mathrm{f}_{\mathrm{i}}$ & $\%$ \\
\hline 1 & Net Revenue & $` 000 € / \$$ & 47 & 100 \\
\hline 2 & Return On Invested Capital & Ratio & 3 & 6,4 \\
\hline 3 & ROE & Ratio & 32 & 68,1 \\
\hline 4 & ROA & Ratio & 29 & 61,7 \\
\hline 5 & Liquidity ratio & Ratio & 16 & 34,0 \\
\hline 6 & EBITDA & $‘ 000 € / \$$ & 47 & 100 \\
\hline 7 & Net Income & $` 000 € / \$$ & 47 & 100 \\
\hline 8 & CAPEX & $` 000 € / \$$ & 47 & 100 \\
\hline 9 & Net Debts & Ratio & 27 & 57,4 \\
\hline 10 & Gross Value Added & $\%$ & 6 & 12,8 \\
\hline 11 & Earnings per share & Ratio & 19 & 40,4 \\
\hline 12 & Operational Revenues & $` 000 € / \$$ & 13 & 27,7 \\
\hline 13 & Contribution Margin & $\%$ & 9 & 19,1 \\
\hline 14 & Volume of Exportations & $\%$ & 6 & 12,8 \\
\hline 15 & Employee Costs & $‘ 000 € / \$$ & 25 & 53,2 \\
\hline
\end{tabular}

Source: Corporate Annual Reports

Financial indicators are the most immediate and visible from the perspective of an actual or potential stockholder. Companies usually disclose return indicators, such as Earnings before Interests, Taxes, Depreciation and Amortisation (EBITDA), Net Income, Capital Expenditures (CAPEX), Return on Assets (ROA) and/or Return on Equity (ROE). Accounting-based measures, such as Net Revenue, Net Income, and 
Net Debts, are also disclosed. However, in case those indicators act as a red flag (with negative signal), they are not explicitly disseminated. Petrol and energy observes major frequency in the dissemination of those indicators.

Table 2. Main Market KPI indicators

\begin{tabular}{|c|l|l|c|c|}
\hline KPI & \multicolumn{1}{|c|}{ Description } & Measure & $\mathrm{f}_{\mathrm{i}}$ & $\%$ \\
\hline 1 & Customer satisfaction index & Index & 9 & 19.1 \\
\hline 2 & Customers satisfaction index & Index & 19 & 40.4 \\
\hline 3 & Number of customers & $\Delta \#$ & 31 & 66.0 \\
\hline 4 & Brands recognition index & Index & 3 & 6.4 \\
\hline 5 & Market share & $\%$ & 19 & 40.4 \\
\hline 6 & Number of Distribution Channels & $\Delta \%$ & 9 & 19.1 \\
\hline 7 & Revenue by segment & $‘ 000 € / \$$ & 6 & 12.8 \\
\hline 8 & Quality score (certification standards) & Score & 16 & 34.0 \\
\hline 9 & Complaints resolution cycle (days) & Days & 11 & 23.4 \\
\hline 10 & Turnover by geographical market & '000 $€ / \$$ & 28 & 59.6 \\
\hline 15 & Commercial alliances & $\#$ & 10 & 21.3 \\
\hline
\end{tabular}

Source: Corporate Annual Reports

In the market perspective, companies tend to disseminate more aggregated indicators, such as satisfaction or quality indexes. Most of them relate to customer satisfaction and efficiency in the complaint procedures. Furthermore, and as observed in the set of indicators for other perspectives, they are compared in most cases with the marks achieved in the previous periods. This allows stakeholders' a dynamic perspective on the indicator variations and trends.

Table 3. Main Internal Process KPI indicators

\begin{tabular}{|c|l|l|l|l|}
\hline KPI & \multicolumn{1}{|c|}{ Description } & Measure & \multicolumn{1}{c|}{$\mathrm{f}_{\mathrm{i}}$} & \multicolumn{1}{c|}{$\%$} \\
\hline 1 & Environmental certifications & $\#$ & 25 & 53.2 \\
\hline 2 & Costs reductions & $\%$ & 16 & 34.0 \\
\hline 3 & Quality certifications & $\#$ & 44 & 93.6 \\
\hline 4 & Inventories rotation & Days & 17 & 36.2 \\
\hline 5 & Rejection rate & $\%$ & 4 & 8.5 \\
\hline 6 & Claims frequency & $\#$ & 6 & 12.8 \\
\hline 7 & Scraps and rejection rate & $\%$ & 3 & 6.4 \\
\hline 8 & Emergency calls & Average & 4 & 8.5 \\
\hline 9 & Machinery productivity & Ratio & 9 & 19.1 \\
\hline 10 & Accidents at work & $\#$ & 3 & 6.4 \\
\hline
\end{tabular}

Source: Companies' Annual Reports 
Internal processes and learning and growth indicators in external reports assume residual nature. Companies do not disseminate information that can be critical from a strategic point of view. Thus, in this perspective, companies usually inform about quality certifications (93.6\%), overall costs rationalisation (34\%), and machinery productivity (19.1\%). As mentioned by Kaplan and Norton (1996:93), "All companies are now attempting to improve quality, reduce cycle times, increase yields, maximize throughput, and lower costs for their business process".

Table 4. Main Learning and Growth KPI indicators

\begin{tabular}{|c|l|l|c|c|}
\hline KPI & \multicolumn{1}{|c|}{ Description } & \multicolumn{1}{c|}{ Measure } & $\mathrm{f}_{\mathrm{i}}$ & \multicolumn{1}{c|}{$\%$} \\
\hline 1 & R\&D as a percentage of sales & $\%$ & 12 & 25.5 \\
\hline 2 & Variation in the Internet visits per month & $\Delta \#$ & 14 & 29.8 \\
\hline 3 & Qualified employees (higher education training) & $\%$ & 27 & 57.5 \\
\hline 4 & Current IT useful lives & Years & 2 & 4.3 \\
\hline 5 & Employee satisfaction & Index & 3 & 6.4 \\
\hline 6 & Training expenditures as percentage of total revenue & $\%$ & 17 & 36.2 \\
\hline 7 & Full time employees & $\%$ & 29 & 61.7 \\
\hline 8 & Human capital return on investment & Ratio & 1 & 2.1 \\
\hline 9 & Severity of accidents at work & Scale & 3 & 6.4 \\
\hline 10 & Investments in ICT & '000 $€ / \$$ & 32 & 68.1 \\
\hline
\end{tabular}

Source: Corporate Annual Reports

The learning and growth perspective is probably the most sensitive field in terms of performance analysis. It relates to human resources and technologies and is associated to capabilities and subsequent productivity. This perspective stresses the importance of investing in other areas, such as information and communication technologies (ICT) and research and development (R\&D). Thus, companies disseminate some key performance indicators, however characterised by their generic nature. The most disclosed KPI are: Investments in ICT (68.1\%); Full-Time Employees (61.7\%); Qualified Employees (57.5\%); Variation in Internet Visits per Month (29.8\%); and $\mathrm{R} \& \mathrm{D}$ as a percentage of sales (25.5\%).

As evidenced in the tables above, multiple performance indicators are disclosed by listed companies in their periodical management reports. Those indicators are usually complemented with brief commentaries about their evolution and trends. The KPI disclosed are consistent with literature review, in particular in Parmenter (2007). However, the variety of indicators observed does not permit a comparison between companies neither between activity sectors. Thus, based on the most disseminated indicators by the companies under analysis, we propose the following twenty key performance indicators. 
Table 5. Scoreboard framework

\begin{tabular}{|l|l|l|l|l|l|}
\hline Financial Perspective & $\mathrm{FY}_{\mathrm{N}}$ & $\mathrm{FY}_{(\mathrm{N}-\mathrm{l})}$ & KPI & $\mathrm{FY}_{\mathrm{N}}$ & $\mathrm{FY}_{(\mathrm{N}-1)}$ \\
\hline KPI & & & Customer Satisfaction & & \\
\hline Net Revenue & & & Number of Customers & & \\
\hline EBITDA & & & Market Share & & \\
\hline Net Income & & & Quality Score & & \\
\hline CAPEX & & & Segmented Turnover & & \\
\hline ROE & $\mathrm{FY}_{\mathrm{N}}$ & $\mathrm{FY}_{(\mathrm{N}-1)}$ & KPI & $\mathrm{FY}_{\mathrm{N}}$ & $\mathrm{FY}_{(\mathrm{N}-1)}$ \\
\hline Internal Process Perspective & & & Investment in ICT & & \\
\hline KPI & & & Full-Time Employees & & \\
\hline Cost Reduction & & & Training Expenditure & & \\
\hline Certifications & & & Qualified Employees & & \\
\hline Inventories Rotation & & & Internet Visits & & \\
\hline Machinery Productivity & & & Learning and Growth Perspective \\
\hline Claims Frequency & & & & \\
\hline
\end{tabular}

The scoreboard proposed above intends to facilitate performance analysis by stakeholders, including the evolution and trends of KPIs. However, information about company performance is still disseminated on a voluntary basis, leading the companies and stakeholders to a systematic asymmetrical dialogue (Gowthrope, 2004). As referred in FASB (2000), the internet has increased the amount and type of data disclosed and has enabled the communication process with previously unidentified consumers of information. In this perspective, we have perceived that in recent years companies have improved the quality of information disclosed, including its categorisation according to different classes of stakeholders. In the context of regulated markets, further developments are required, in particular in the domain of policy making. Information disclosed to the market is not sufficiently regulated in order to minimise the performance analysis discretion and overall transparency. Thus, agency conflicts still remain between companies and stockholders, influencing the gap between company market and accounting (equity) values.

\section{Lessons Learned and Directions}

In this research we have presented an overall overview of the performance indicators disseminated through the internet to stakeholders, in particular to potential stockholders. Regulated markets require the disclosure of information through company websites, namely the financial information, press releases, and other announcements. However, information about KPI is still disclosed on a voluntary basis and in non-structured forms. From stakeholder perspective, this does not permit any comparison between companies or even activity sectors. Some companies disseminate 
a set of indicators directly on their websites, while others integrate those indicators in their management reports. Based on the most disseminated indicators effectively disclosed, we have proposed a scoreboard framework for a four perspective analysis.

As other studies and approaches, this research has its intrinsic limitations. First, the sample used is limited to Portuguese listed companies on Euronext regulated market. Second, the selection of indicators was based exclusively on frequencies and not on the value and importance attributed by stakeholders to those indicators. This approach does not ensure that the selected indicators are the ones that best fit stakeholder expectations and needs. Third, this research was also based on websites and management report analysis which introduces a certain level of subjectivity, a natural source of interpretation bias.

This paper also intends to guide researchers for further directions, namely on the topic of information quality and transparency. Web-based reporting is moving ahead very quickly, requiring new policies and rules from value system agents, in particular business regulators, to minimise agency conflicts and agency costs. The main and fruitful research directions can be to surpass the intrinsic limitations of this paper.

\section{References}

Abraham, S.; Cox, P. 2007. "Analyzing the determinants of narrative risk information in UK FTSE 100 annual reports", The British Accounting Review, 39(3): 227-248.

Al-Shammari, B.; Brown, P.; Tarca, A. 2008. "An investigation of compliance with international accounting standards by listed companies in the Gulf Co-Operation Council Member States", The International Journal of Accounting, 43(4): 425-447.

Aly, D.; Simon, J.; Hussainey, K. 2010. "Determinants of corporate internet reporting: evidence from Egypt", Managerial Auditing Journal, 25(2): 182-202.

Arrow, K. 1971. Essays in the theory of risk bearing, Chicago: Markham.

Arvidsson, S. 2011. "Disclosure of non-financial information in the annual reports", Journal of Intellectual Capital, 12(2): 277-300.

Asbaugh, H.; Johnstone, K. M.; Warfield, T. D. 1999. "Corporate Reporting on the Internet", Accounting Horizons, 13(3): 241-257.

Basu, A.; Lal, R.; Srinivasan, V.; Staelin, R. 1985. "Sales force compensation plans: An agency theoretic perspective", Marketing Science, 4: 267-291.

Basuony, M. A.; Mohamed, E. K. 2014. "Determinants of Internet Financial
Disclosure in GCC Countries", Asian Journal of Finance \& Accounting, 6(1): 70-89.

Barako, D. G.; Hancock, P.; Izan, H. Y. 2006. "Factors influencing voluntary corporate disclosure by Kenyan companies", Corporate Governance: An International Review, 14(2): 107-125.

Broberg, P.; Tagesson, T.; Collin, S. 2010. "What explains variation in voluntary disclosure? A study of the annual reports of corporations listed on the Stockholm Stock Exchange", Journal of Management and Governance, 14: 351-377.

Demski, J. 1980. "A simple case of indeterminate financial reporting”, working paper, Stanford University, Stanford, CA.

DiMaggio, P.; Powell, W. 1991. “The iron Cage Revisited: Institutional Isomorphism and Collective Rationality in organization fields, in: Powell, W. and DiMaggio, P. (Eds.) The New Institutionalism in Organizational Analysis, Chicago: The University of Chicago Press.

Dowling, J.; Pfeffer, J. 1975. “Organizational Legitimacy: Social Values and Organizational Behaviour", Pacific Sociological Review, 18(1): 122-136. 
Dragu, I.; Tudor, A. T. 2011. "Developing an econometric model for measuring the evolution of information disclosure - IAS 23 Borrowing costs", Annales Universitatis Apulensis Series Oeconimica, 13(2): 254-259.

Eisenhardt, K. M. 1985. “Control: Organizational and economic approaches", Management Science, 31: 134-149.

Eisenhardt, K. M. 1989. "Agency theory: an assessment and review", Academy of Management Review, 14(1): 57-74.

FASB - Financial Accounting Standards Board 2000. "Electronic distribution of business reporting information", Business Reporting Research Project, [interactive]. [accessed 2014-05-14]. <http://www.fasb.org/brrp/ brrp1.shtml>.

Fama, E. 1980. "Agency problems and the theory of the firm", Journal of Political Economy, 88: 288-307.

Fontrodona, J.; Sison, A. J. G. 2006. “The Nature of the Firm, Agency Theory and Shareholder Theory: A Critique from Philosophical Anthropology", Journal of Business Ethics, 66: 33-42.

Guthrie, J.; Petty; R.; Yongvanich, K.; Ricceri, F. 2004. "Using Content analysis as a Research Method to Inquire into Intellectual Capital Reporting", Journal of Intellectual Capital, 5 (2): 282-293.

Gowthorpe, C. 2004. “Asymmetrical dialogue? Corporate financial reporting via the Internet", Corporate Communications, 9(4): 283-293.

Hunter, S. A.; Smith, L. M. 2009. "Impact of Internet Financial Reporting on Emerging Markets", Journal of International Business Research, 8(2): 21-40.

Jensen, M.; Meckling, W. 1976. "Theory of the firm: managerial behaviour, agency costs, and ownership structure", Journal of Financial Economics, 3: 305-360.

Kaplan, R.; Norton, D. 1996. The Balanced Scorecard: translating strategy into action, Boston: Harvard Business School Press.

Kosnik, R. 1987. "Greenmail: A study in board performance in corporate governance", Administrative Science Quarterly, 32: 163185.
Khadaroo, M. I. 2005. "Business reporting on the internet in Malaysia and Singapore: a comparative study", Corporate Communications, 10(1): 58-68.

Kulik, B. W. 2005. “Agency Theory, Reasoning and Culture at Enron: In search of a Solution", Journal of Business Ethics, 59: 347-360.

Mitnick, B. 1986. "The theory of agency and organizational analysis", University of Pittsburgh.

Mutawaa, A.; Hewaidy, A. 2010. "Disclosure Level and Compliance with IFRSs: An empirical investigation of Kuwaiti companies", The International Business \& Economics Research Journal, 9 (5): 33-49.

Oyelere, P.; Kuruppu, N. 2012. "Voluntary internet financial reporting practices of listed companies in the United Arab Emirates", Journal of Applied Accounting Research, 13(3): 298-315.

Parmenter, D. 2007. Key Performance Indicators: Developing, Implementing, and Using Winning KPIs, New Jersey: John Wiley \& Sons.

Ross, S. 1973. "The economic theory of agency: The principal's problem", American Economic Review, 63: 13-139.

Ryan, B.; Scapens, W.; Theobald, M. 2002. Research method \& Methodology in Finance \& Accounting, $2^{\text {nd }}$ edition, Thomson, London.

Sekaran, U.; Bougie, R. 2013. Research Methods for Business, Sixth Edition, John Wiley \& Sons, West Sussex.

Shapiro, S. P. 2005. "Agency Theory”, Annual Review of Sociology, 31: 263-284.

Spence, A. M.; Zeckhauser, R. 1971. "Insurance, information, and individual action", American Economic Review, 61: 380-387.

Street,D.L.; Gray, S.J. 2002. “Factorsinfluencing the extent of corporate compliance with international accounting standards: summary of a research monograph", Journal of International Accounting, Auditing and Taxation, 11: 51-76.

Tapscott, D.; Ticoll, D.; Lowy, A. 2000. Digital Capital - Harnessing the Power of Business 
Webs, Boston: Harvard Business School Press.

Thomas, A. 1991. "Towards a Contingency Theory of Corporate Financial Reporting System", Accounting, Auditing \& Accountability Journal, 4(4): 40-57.

Uyar, A. 2012. "Determinants of corporate reporting on the internet", Managerial Auditing Journal, 27(1): 87-104.

Verecchia, R. E. 2000. "Discretionary disclosure", Journal of Accounting and Economics, 5: 179-194.

Wallace, R. S.; Naser, K.; Mora, A. 1994. "The relationship between the comprehensiveness of corporate annual reports and firm characteristics in Spain", Accounting and Business Research, 25: 41-53.
Wallace, R. S.; Naser, K. 1995. "Firm-specific determinants of the comprehensiveness of mandatory disclosure in the corporate annual reports and firms listed on the stock exchange of Hong Kong”, Journal of Accounting and Public Policy, 14(4): 311-368.

Watson, A.; Shrives, P.; Martson, C. 2002. "Voluntary disclosure of accounting ratios in the UK", British Accounting Review, 34: 289-313.

White, H. 1985. "Agency as control”, In J. Pratt and R. Zeckhaouser (Eds.), Principles and agents: The structure of business (p.: 187-214), Boston: Harvard Business School Press.

Wilson, R. 1968. "On the theory of syndicates", Êconometrica, 36: 119-132. 